ARTICLE

DOI: $10.1038 / s 41467-017-01340-7$

OPEN

\title{
Bioluminescence imaging of $G$ protein-coupled receptor activation in living mice
}

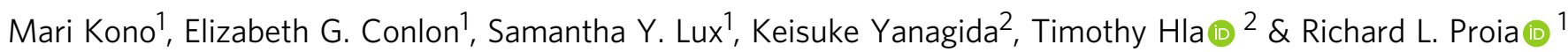

G protein-coupled receptors (GPCRs), a superfamily of cell-surface receptors involved in virtually all physiological processes, are the major target class for approved drugs. Imaging GPCR activation in real time in living animals would provide a powerful way to study their role in biology and disease. Here, we describe a mouse model that enables the bioluminescent detection of GPCR activation in real time by utilizing the clinically important GPCR, sphingosine-1-phosphate receptor $1\left(\mathrm{~S}_{1} \mathrm{P}_{1}\right)$. A synthetic $\mathrm{S}_{1} \mathrm{P}_{1}$ signaling pathway, designed to report the interaction between $\mathrm{SIP}_{1}$ and $\beta$-arrestin2 via the firefly split luciferase fragment complementation system, is genetically encoded in these mice. Upon receptor activation and subsequent $\beta$-arrestin2 recruitment, an active luciferase enzyme complex is produced, which can be detected by in vivo bioluminescence imaging. This imaging strategy reveals the dynamics and spatial specificity of $\mathrm{STP}_{1}$ activation in normal and pathophysiologic contexts in vivo and can be applied to other GPCRs.

\footnotetext{
${ }^{1}$ Genetics of Development and Disease Branch, National Institute of Diabetes and Digestive and Kidney Diseases, NIH, Bethesda, MD 20892, USA

${ }^{2}$ Vascular Biology Program, Boston Children's Hospital, Department of Surgery, Harvard Medical School, Boston, MA 02115, USA. Correspondence and requests for materials should be addressed to R.L.P. (email: richardp@intra.niddk.nih.gov)
} 
protein-coupled receptors (GPCRs) (also known as seven-transmembrane-domain receptors) are the largest and most diverse gene superfamily in the human genome, comprising greater than $3 \%$ of the protein coding genes ${ }^{1-3}$. GPCRs are widely expressed, initiate cellular signal transduction by a diverse array of extracellular ligands, and are involved in virtually all physiological functions ${ }^{1,4}$. They are also extremely important in clinical medicine as a major drug target class. It is estimated that $\sim 30 \%$ of approved pharmaceutical drugs are directed to GPCRs ${ }^{4,5}$. Despite their enormous biological and clinical importance, technologies to image GPCR activation in their native physiologic environment in real time are lacking, hampering a full understanding of the spatiotemporal dynamics of their activation in vivo by endogenous or exogenous ligands.

Sphingosine-1-phosphate receptor $1\left(\mathrm{~S}_{1} \mathrm{P}_{1}\right)$ is one of a fivemember GPCR family with high affinity for the bioactive sphingolipid, sphingosine-1-phosphate (S1P). It is ubiquitously expressed among tissues and is highly enriched in endothelial cells, where it serves as a key regulator of vascular barrier function ${ }^{6-8} . \mathrm{S}^{\mathrm{P}} \mathrm{P}_{1}$ also performs important actions in the immune and nervous systems ${ }^{7}$. Its endogenous sphingolipid ligand, S1P, is produced by all cells and is carried by lipoproteins and albumin in the circulation ${ }^{7} . \mathrm{S} 1 \mathrm{P}-\mathrm{S} 1 \mathrm{P}_{1}$ signaling has been linked to diverse disease processes, including infection, multiple sclerosis, atherosclerosis, inflammatory bowel disease, and cancer ${ }^{6,7,9}$. FTY720 (fingolimod/Gilenya ${ }^{\mathrm{TM}}$ ), an $\mathrm{S}_{1} \mathrm{P}_{1}$ ligand, is an FDA-approved drug for the treatment of remitting-relapsing multiple sclerosis ${ }^{10}$.

Ligand-activated GPCRs stimulate intracellular signaling pathways via $G$ proteins ${ }^{11,12}$ and other effectors, including $\beta$ arrestins $^{13-16}$. $\beta$-Arrestin binding to activated GPCRs also mediates receptor desensitization, internalization, and recycling. The near-universal interaction between GPCRs and $\beta$-arrestins following agonist binding has been employed in assays for quantifying receptor activation ${ }^{17-21}$. We recently developed a mouse model for the detection of activated $\mathrm{S}_{1} \mathrm{P}_{1}$ in which a green fluorescent protein (GFP) reporter gene was activated ${ }^{22}$. This model enabled the identification of cells in which receptor activation has occurred in a cumulative manner, but it is not suited for intravital imaging of real-time activation of GPCR signaling.

Here, we describe a genetic model in mice that enables the imaging of $\mathrm{S}_{1} \mathrm{P}_{1}$ signaling in real time in the native physiological environment of the receptor. These $\mathrm{S}_{1} \mathrm{P}_{1}$ signaling mice were genetically designed to report the interaction between $\mathrm{S}_{1} \mathrm{P}_{1}$ and $\beta$ arrestin2 upon receptor activation via firefly split luciferase fragment complementation, which produces an active enzyme complex whose activity can be detected by bioluminescence imaging. The $\mathrm{S}_{1} \mathrm{P}_{1}$ signaling mice respond to synthetic ligands in accordance to the specificity of the native receptor and the stability of pharmacologic agonists. The $\mathrm{S}_{1} \mathrm{P}_{1}$ signaling mice also reveal the timing and anatomical localization of receptor activation by the endogenously synthesized S1P ligand during endotoxin-induced systemic inflammation. This paradigm can be applied to other members of the clinically important GPCR family to enable the study of receptor activation in their in vivo settings.

\section{Results}

Generation of $\operatorname{S1P}_{1}$ luciferase signaling mice. Our strategy for imaging the activation of a GPCR in real time in living mice was to adapt a firefly split luciferase complementation system ${ }^{21,23,24}$ for the detection of the interaction between ligand-activated $\mathrm{S}_{1} \mathrm{P}_{1}$ and $\beta$-arrestin2 (Fig. 1a). Both $\mathrm{S}_{1} \mathrm{P}_{1}$ and $\beta$-arrestin2 were genetically modified as individual fusion proteins to carry inactive, but complementary, fragments of luciferase. The $\mathrm{S}_{1} \mathrm{P}_{1} \mathrm{C}$ terminus was linked to the C-terminal fragment of firefly luciferase (CLuc: amino acids \#394-550), and the $\beta$-arrestin2 $\mathrm{N}$ terminus was linked to the $\mathrm{N}$-terminal fragment of firefly luciferase (NLuc: amino acids \#1-416). In this scheme, $\mathrm{S}_{\mathrm{P}} \mathrm{P}_{1}$ activation will promote its interaction with $\beta$-arrestin2, facilitating the association of the inactive luciferase fragments and producing an active enzyme complex that, in the presence of substrates ATP and D-luciferin, generates light that can be detected by bioluminescence imaging (BLI).

The efficacy and specificity of the split luciferase complementation system for detection of $\mathrm{S}_{1} \mathrm{P}_{1}$ activation was tested by cotransfection of expression vectors containing the $\mathrm{S}_{1} \mathrm{P}_{1}-\mathrm{CLuc}$ and NLuc- $\beta$-arrestin 2 fusion genes into U2OS cells. As a negative interaction control, NLuc was fused to herpes simplex virus thymidine kinase (HSV-tk) in place of $\beta$-arrestin2, and cotransfected with $\mathrm{S}_{1} \mathrm{P}_{1}-\mathrm{CLuc}$. In transfected cells treated with vehicle, minimal luciferase activity was detected (Supplementary Fig. 1a, b). However, addition of S1P or RP-001, a synthetic S1P $1^{-}$ selective agonist ${ }^{25}$, caused a significant increase in luciferase activity in the $S 1 \mathrm{P}_{1}-\mathrm{CLuc} / \mathrm{NLuc}-\beta$-arrestin2-transfected cells compared with the $\mathrm{S}_{1} \mathrm{P}_{1}-\mathrm{CLuc} / \mathrm{NLuc}-\mathrm{HSV}$-tk-transfected cells. These results demonstrate that the split luciferase complementation system, utilizing $\mathrm{S}_{1} \mathrm{P}_{1}$ and $\beta$-arrestin fusions, can specifically detect $\mathrm{S}_{1} \mathrm{P}_{1}$ activation.

Gene targeting in embryonic stem cells was employed to produce two individual mouse lines, each carrying one of the fusion constructs (Supplementary Fig. 2a, b). One mouse line was generated with the $\mathrm{S}_{1} \mathrm{P}_{1}-\mathrm{CLuc}$ fusion knocked in to the $\mathrm{S}_{1} \mathrm{P}_{1}$ coding region. In this configuration, the native $\mathrm{S}_{1} \mathrm{P}_{1}$ promoter elements were maintained to allow for expression of the $\mathrm{S}_{1} \mathrm{P}_{1}$ fusion gene in the endogenous context. The other mouse line was established with the NLuc- $\beta$-arrestin 2 fusion knocked in to the safe harbor Rosa26 locus under control of the Rosa26 promoter elements to provide a ubiquitous expression pattern, ensuring that NLuc- $\beta$-arrestin 2 would be co-expressed along with $\mathrm{S}_{1} \mathrm{P}_{1}-\mathrm{CLuc}$. The $\mathrm{S}_{1} \mathrm{P}_{1}-\mathrm{CLuc}$ knock-in mice were crossed with the NLuc- $\beta$-arrestin 2 knock-in mice to derive mice carrying both alleles (Fig. 1a), which are termed $\mathrm{S}_{1} \mathrm{P}_{1}$ luciferase signaling mice.

To determine whether the synthetic $\mathrm{S}_{1} \mathrm{P}_{1}$ signaling pathway genetically encoded within the $S 1 \mathrm{P}_{1}$ luciferase signaling mice was responsive to ligands with specificity similar to native $S 1 P_{1}$, primary mouse embryonic fibroblasts (MEFs) derived from $\mathrm{S}_{1} \mathrm{P}_{1}$ luciferase signaling mice were utilized. Addition of S1P but not vehicle rapidly induced bioluminescence in the MEFs (Fig. 1b). Bioluminescence activity peaked within $3 \mathrm{~min}$ after addition of S1P to the MEFs and was rapidly lost thereafter (Fig. 1b). This loss of activity indicates that luciferase fragment complementation is transient and may reflect the rapid kinetics of $\mathrm{S}_{1} \mathrm{P}_{1}$ desensitization after activation and the subsequent dissociation of the receptor- $\beta$-arrestin 2 complex $^{26}$. S1P and RP-001, a potent synthetic $\mathrm{S}_{\mathrm{P}} \mathrm{P}_{1}$-selective agonist ${ }^{25}$, induced luciferase activity in the $\mathrm{S}_{1} \mathrm{P}_{1}$ luciferase signaling MEFs, but not in MEFs carrying only the $\mathrm{S}_{1} \mathrm{P}_{1}-\mathrm{CLuc}$ or the NLuc- $\beta$-arrestin2 alleles (Fig. $1 \mathrm{~b}, \mathrm{c}$ ), showing that both components of the genetically encoded split luciferase complementation system were necessary to report the ligand-activated $\mathrm{S}_{1} \mathrm{P}_{1}-\mathrm{CLuc}$ interaction with NLuc- $\beta$-arrestin2. Two structural analogs of S1P, lysophosphatidic acid (LPA) and sphingosine, that are not ligands for $\mathrm{S}_{1} \mathrm{P}_{1}$ did not induce bioluminescence when added to $\mathrm{S}_{1} \mathrm{P}_{1}$ luciferase signaling MEFs at a concentration of $10^{-6} \mathrm{M}$ (Fig. 1d, e).

The $\mathrm{EC}_{50}$ values for the activation of bioluminescence by S1P and $\mathrm{RP}-001$ in $\mathrm{S}_{1} \mathrm{P}_{1}$ luciferase signaling MEFs were determined to be $19.4 \pm 0.8$ and $0.46 \pm 0.02 \mathrm{nM}$, respectively (Fig. 1f). The natural ligand dihydro-S1P $(\mathrm{dhS} 1 \mathrm{P})^{27}$, exhibited an $\mathrm{EC}_{50}$ for the activation of bioluminescence of $32.4 \pm 0.5 \mathrm{nM}$. 
a

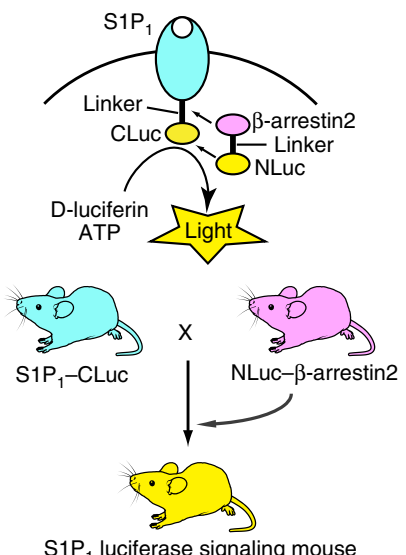

$\mathrm{S}_{1} \mathrm{P}_{1}$ luciferase signaling mouse

$\left(\mathrm{S} 1 \mathrm{P}_{1} \mathrm{LS}\right)$ b

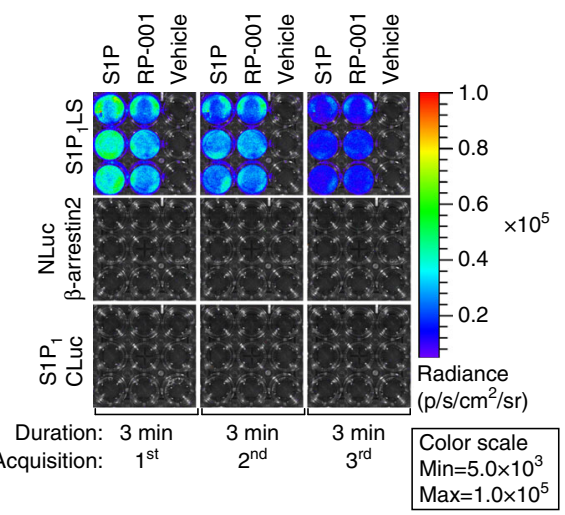

C

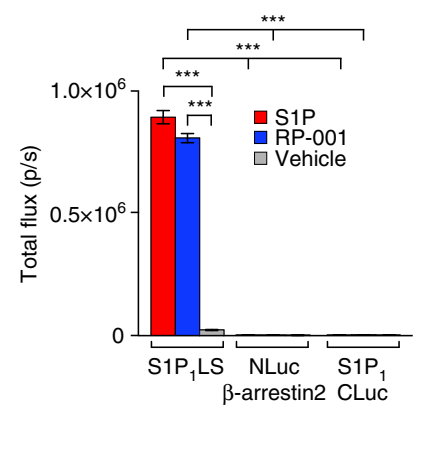

d

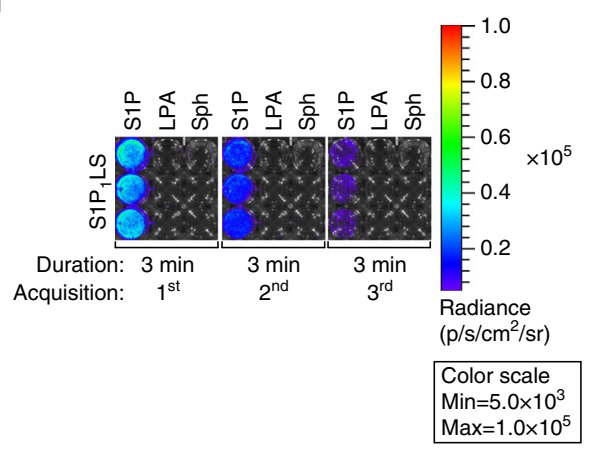

e

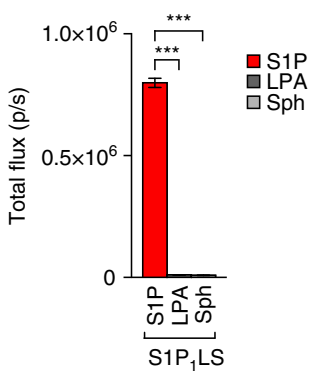

f

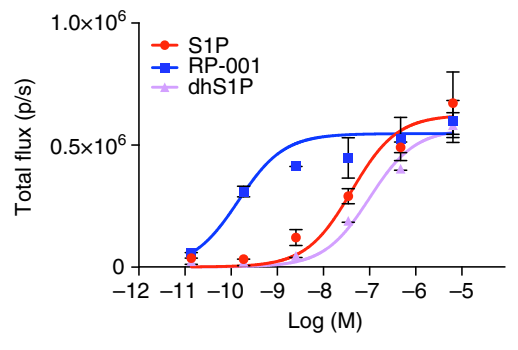

g

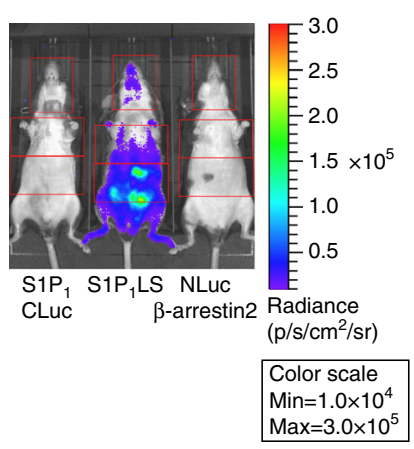

h

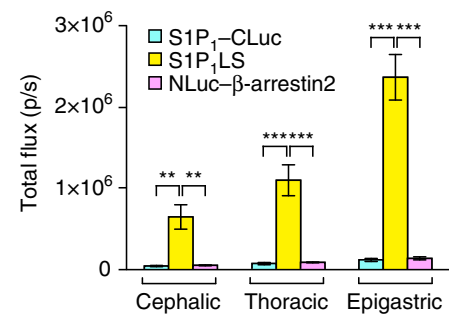

i

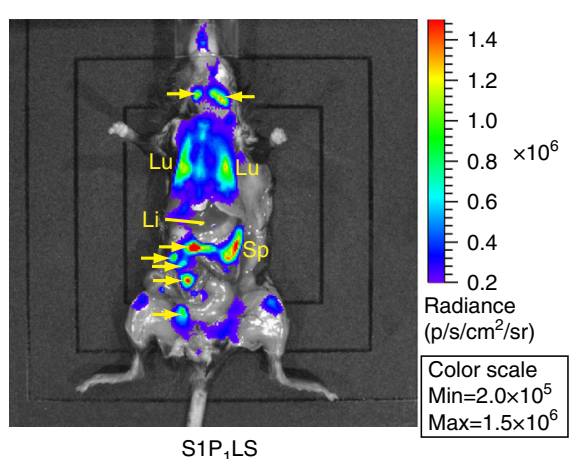

Fig. 1 Generation of $\mathrm{STP}_{1}$ luciferase signaling mice and detection of $\mathrm{S}_{\mathrm{P}}$ activation. a (top), Schematic of the firefly split luciferase complementation design

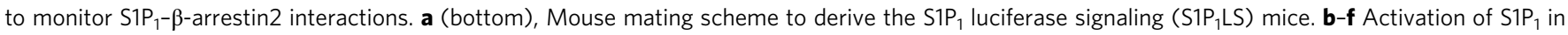
MEFs. b S1P 1 luciferase signaling (S1P 1 LS) MEFs heterozygous for the S1P ${ }_{1}-C L u c$ allele and homozygous for the NLuc- $\beta$-arrestin2 allele, MEFs heterozygous for the $\mathrm{S1P}_{1}$-CLuc allele, and MEFs homozygous for the NLuc- $\beta$-arrestin2 allele were treated with S1P, RP-001 (10-6 M), or vehicle in triplicate, and immediately subjected to BLI. Intensities are shown in units of photons $/ \mathrm{sec} / \mathrm{cm}^{2} / \mathrm{steradian}^{\mathrm{p}} \mathrm{sec} / \mathrm{cm}^{2} / \mathrm{sr}$. c The bioluminescence from three sequential 3-

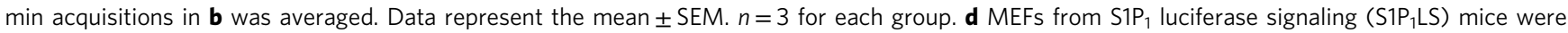
exposed to S1P, sphingosine (Sph), or LPA $\left(10^{-6} \mathrm{M}\right)$ in triplicate, and immediately subjected to BLI. Imaging was for sequential 3-min periods. e The bioluminescence from three sequential 3-min acquisitions in $\mathbf{d}$ was averaged. Data represent the mean $\pm S E M, n=3$ for each group. Experiments in $\mathbf{b}$ and $\mathbf{d}$ were repeated twice. $\mathbf{f}$ Dose-response of $\mathrm{S}_{\mathrm{P}}$ activation in $\mathrm{S}_{1} \mathrm{P}_{1}$ luciferase signaling MEFs. MEFs derived from S1P luciferase signaling mice, then exposed in triplicate to various concentrations of S1P, RP-001, or dhS1P and immediately subjected to BLI for 30 min. The experiment was repeated twice. Data represent the mean \pm SEM. $\mathbf{g}, \mathbf{h}$ Basal S1P 1 activation in live mice. Three mouse genotypes were analyzed by BLI: heterozygous for the S1P ${ }_{1}$-CLuc allele $\left(\mathrm{S} 1 \mathrm{P}_{1}-\mathrm{CLuc}\right)$; homozygous for the NLuc- $\beta$-arrestin2 allele (NLuc- $\beta$-arrestin2); and heterozygous for the S1P $\mathrm{P}_{1}$ CLuc allele and homozygous for the NLuc- $\beta$ arrestin2 allele $\left(\mathrm{S}_{1} \mathrm{P}_{1} \mathrm{LS}\right)$. $\mathbf{g}$ A representative image comparing the basal bioluminescence activity in the three mouse lines. Mice were imaged in the supine position. Red open rectangles representing regions of interest (ROI) were positioned around cephalic, thoracic, and epigastric regions. $\mathbf{h}$ The bioluminescence activity was quantified by determining the total flux (photons/sec; p/sec) in each ROI. Data represent the mean $\pm S E M$. $n=5$ for $\mathrm{S}_{1} \mathrm{P}_{1}$-CLuc, $n=8$ for $\mathrm{STP}_{1} \mathrm{LS}, n=5$ for NLuc- $\beta$-arrestin2. i Basal S1P $\mathrm{P}_{1}$ activation in internal organs. S1P 1 luciferase signaling $\left(S 1 \mathrm{P}_{1} \mathrm{LS}\right)$ mice $(n=3)$. A representative image is shown (supine view). Arrow lymph node, Li liver, Sp spleen, Lu lung. $P$ values were determined by one-way ANOVA followed by Tukey's multiple comparisons test; ${ }^{\star \star} P \leq 0.01,{ }^{\star \star \star} P \leq 0.001$ 
To determine if the genetically encoded split luciferase complementation system could detect basal $\mathrm{S}_{1} \mathrm{P}_{1}$ activation in vivo, $\mathrm{S} \mathrm{P}_{1}$ luciferase signaling mice, as well as mice carrying only the $\mathrm{S}_{1} \mathrm{P}_{1}-\mathrm{CLuc}$ or NLuc- $\beta$-arrestin 2 alleles, were subjected to BLI while under anesthesia. Significantly higher levels of bioluminescence activity were detected in the $\mathrm{S}_{1} \mathrm{P}_{1}$ luciferase signaling mice compared with the mice carrying only the $\mathrm{S}_{1} \mathrm{P}_{1}-\mathrm{CLuc}$ or NLuc- $\beta$-arrestin2 alleles (Fig. 1g). We quantified bioluminescence activity in the cephalic, thoracic, and epigastric regions, as the activity varied between different body regions. The highest activity was observed in the epigastric region, followed by the thoracic and cephalic regions (Fig. 1h). To identify the anatomical sites of basal $\mathrm{S}_{1} \mathrm{P}_{1}$ activation in $\mathrm{S}_{1} \mathrm{P}_{1}$ luciferase signaling mice, $\mathrm{S}_{1} \mathrm{P}_{1}$ luciferase signaling mice were subjected to BLI after surgically exposing the thoracic region and abdominal cavity. The highest bioluminescence signals were detected in lungs, in lymph nodes, and in the splenic region. Notably, no signal was detected in the liver (Fig. 1i).

Treatment of $S 1 P_{1}$ signaling mice with antagonist. To determine if the bioluminescence activity detected in $\mathrm{S}_{1} \mathrm{P}_{1}$ luciferase signaling mice was the result of endogenous $\mathrm{S}_{1} \mathrm{P}_{1}$ activation, the mice were injected with $\mathrm{W} 146^{28}$, a potent $\mathrm{S}_{1} \mathrm{P}_{1}$-selective antagonist (Fig. 2a). W146 treatment administered 30 min prior to BLI significantly lowered the bioluminescence in the $\mathrm{S}_{1} \mathrm{P}_{1}$ luciferase signaling mice by $70-80 \%$ in a dose-dependent manner in the cephalic, epigastric, and thoracic regions compared with the same mice treated with vehicle (Fig. $2 \mathrm{~b}-\mathrm{d}$ ). The basal bioluminescence activity was completely restored in these $\mathrm{S}_{1} \mathrm{P}_{1}$ luciferase signaling mice 1 day post-W146 injection (Fig. 2b-d), which is consistent with the rapid clearance reported for this compound ${ }^{29}$. The inhibition of bioluminescence activity by an $\mathrm{S}_{1} \mathrm{P}_{1}$ antagonist indicates that the basal activity detected in the live mice is primarily the result of endogenous $\mathrm{S}_{1} \mathrm{P}_{1}$ activation.

Treatment of S1P $\mathbf{P}_{1}$ signaling mice with agonists. FTY720 (fingolimod/Gilenya ${ }^{\mathrm{TM}}$ ), a sphingosine analog, is phosphorylated by sphingosine kinases in vivo, and converted to a form that, at nanomolar concentrations, activates $\mathrm{S}_{1} \mathrm{P}_{1}$, as well as $\mathrm{S}_{1} \mathrm{P}_{3}, \mathrm{~S}_{1} \mathrm{P}_{4}$, and $\mathrm{S}_{1} \mathrm{P}_{5}{ }^{10}$. Its half-life in blood after oral administration in rats is $\sim 24 \mathrm{~h}^{30}$. To determine the time course of $\mathrm{S}_{1} \mathrm{P}_{1}$ activation by FTY720 in the $\mathrm{S}_{1} \mathrm{P}_{1}$ luciferase signaling mice, the mice were imaged prior to the administration of compounds and then imaged serially at $1.5,6,24$, and $48 \mathrm{~h}$ after intraperitoneal injection of each compound (Fig. 3). FTY720 concurrently induced peak levels of bioluminescence activity in the cephalic, thoracic, and epigastric regions at $6 \mathrm{~h}$ after injection. Significant bioluminescence activity continued to be detected at 24 and $48 \mathrm{~h}$ after injection of FTY720, commensurate with the relatively long halflife of the drug. BLI performed on FTY720-treated $\mathrm{S}_{1} \mathrm{P}_{1}$ luciferase signaling mice ( $5 \mathrm{~h}$ after FTY720 treatment) with their internal organs surgically exposed showed highly elevated bioluminescence signals over lung, lymph nodes, spleen, and liver (Supplementary Fig. 3a). Compared with FTY720, RP-001 is a very shortacting $\mathrm{S}_{1} \mathrm{P}_{1}$ agonist that decreases to undetectable levels in blood by $8 \mathrm{~h}$ after administration in mice ${ }^{25}$ but is substantially more potent, being effective at picomolar concentrations. RP-001 a

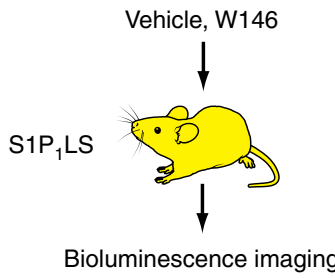

b

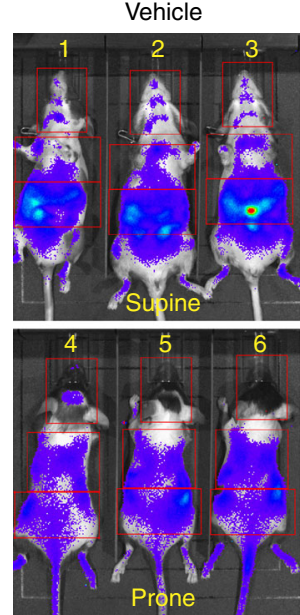

$\mathrm{W} 146,10 \mathrm{mg} / \mathrm{kg}$

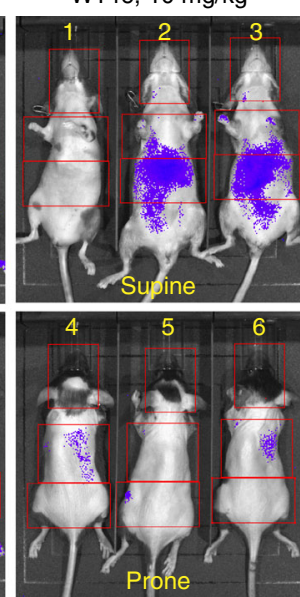

Post W146

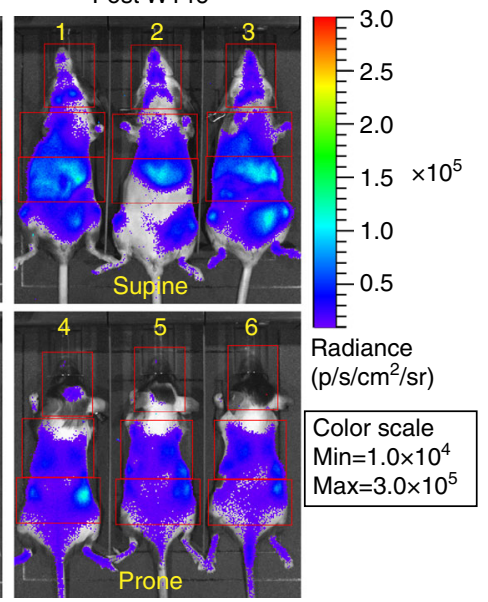

C

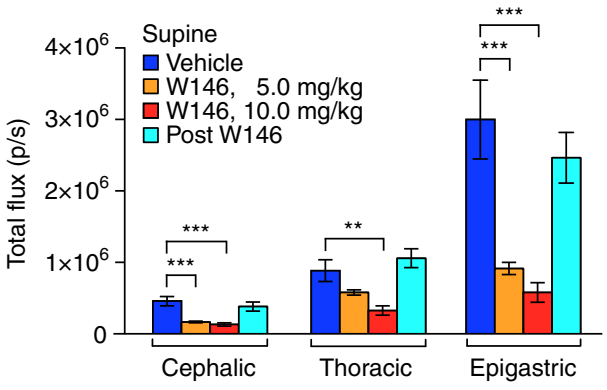

d

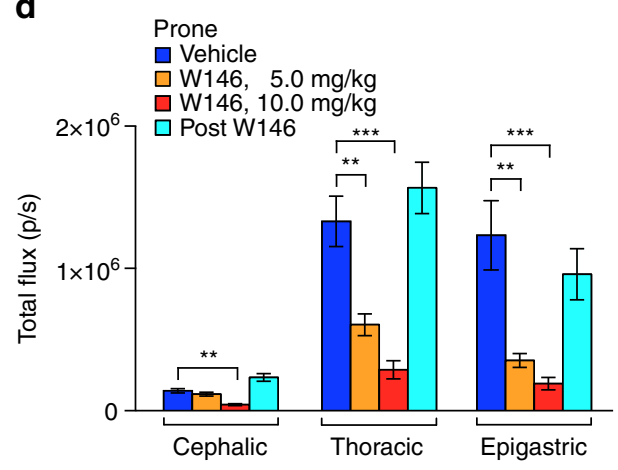

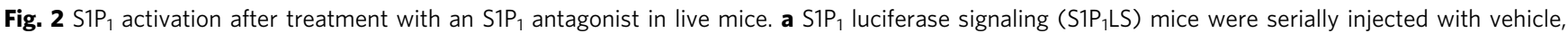
followed by the $\mathrm{S1P}_{1}$ antagonist W146 (5 or $10 \mathrm{mg} / \mathrm{kg}$, ip injection). b Representative repeat bioluminescence images of the same mice (top, supine view of mouse \# 1, 2, 3; bottom, prone view of mouse \# 4,5,6) comparing the effects of vehicle with those of W146 (10 mg/kg), $0.5 \mathrm{~h}$ after injection. BLI was also performed 1 day after the W146 injection (post W146). Red open rectangles representing ROI were positioned around cephalic, thoracic, and epigastric regions. c, d The bioluminescence activity was quantified by determining the total flux (photons/sec; $\mathrm{p} / \mathrm{sec}$ ) in each ROI. Data acquired from supine (c) and prone (d) views are shown. Data represent the mean \pm SEM. $n=6$ for each group. $P$ values were determined by one-way ANOVA followed by Bonferroni's multiple comparisons test; ${ }^{\star \star} P \leq 0.01,{ }^{\star \star \star} P \leq 0.001$ 
induced a peak of bioluminescence activity $1.5 \mathrm{~h}$ after administration to $\mathrm{S}_{1} \mathrm{P}_{1}$ luciferase signaling mice in the cephalic, thoracic, and epigastric regions. The bioluminescence signal was most intense in the epigastric region. By 24 and $48 \mathrm{~h}$ after dosing, the bioluminescence activity in RP-001-treated $\mathrm{S}_{1} \mathrm{P}_{1}$ luciferase signaling mice declined to baseline levels (Fig. 3b-e).

LPS-induced systemic inflammation in $\mathrm{S}_{1} \mathrm{P}_{1}$ signaling mice. $\mathrm{S}_{1} \mathrm{P}_{1}$ signaling is activated during systemic inflammation induced by bacterial lipopolysaccharide (LPS); however, the timing and anatomical distribution of receptor activation is not well established $^{22}$. In order to define these parameters, $\mathrm{S}_{1} \mathrm{P}_{1}$ luciferase signaling mice were intraperitoneally injected with a sublethal dose of LPS and then subjected to serial BLI at 2, 6, 24, 48, 72, and $96 \mathrm{~h}$ (Fig. 4). At $2 \mathrm{~h}$ after injection, a weak increase in bioluminescence was observed primarily in the epigastric region, which returned to baseline levels at $6 \mathrm{~h}$. At $24 \mathrm{~h}$ after administration, the bioluminescent signal was significantly increased in the cephalic and thoracic regions (Fig. 4b, c and Supplementary Fig. 5). At $48 \mathrm{~h}$ after administration, bioluminescent signal was elevated in the thoracic region. At $72 \mathrm{~h}$ after administration, the strongest signal was observed in the epigastric region. At $24 \mathrm{~h}$ after LPS administration, BLI performed in $\mathrm{S}_{1} \mathrm{P}_{1}$ luciferase signaling mice with surgically exposed internal organs demonstrated bioluminescent signals induced over lungs, lymph nodes, spleen, and liver (Supplementary Fig. 3b). These results show that LPS induces heightened $\mathrm{S}_{1} \mathrm{P}_{1}$ activation in a sustained manner systemically. In addition, the timing of $\mathrm{S}_{1} \mathrm{P}_{1}$ activation was distinctive for specific anatomical locations.

LPS-induced S1P ${ }_{1}$ activation by hematopoietically derived S1P. A major fraction of circulating S1P is produced by hematopoietically derived cells ${ }^{31}$. To determine if hematopoietic cell-derived $\mathrm{S} 1 \mathrm{P}$ is critical for systemic $\mathrm{S}_{1} \mathrm{P}_{1}$ activation during LPS-induced inflammation, irradiated $\mathrm{S}_{1} \mathrm{P}_{1}$ luciferase signaling mice were transplanted with sphingosine kinase-deficient bone marrow from plasmaS1Pless mice, which lack the ability to produce S1P in the hematopoietic system ${ }^{31}$, and then subjected to BLI (Fig. 5a). Plasma S1P and dhS1P levels were significantly decreased in the plasmaS1Pless bone marrow-transplanted mice to $\sim 20$ and $10 \%$, respectively, of the levels observed in control bone marrow-transplanted mice (Fig. 5b). The residual S1P and dhS1P in the plasmaS1Pless bone marrow-transplanted mice are likely produced by the sphingosine kinase-replete endothelial cells of the recipient mice ${ }^{32}$. After LPS treatment, mice transplanted with control bone marrow exhibited significantly increased bioluminescence activity compared with the plasmaS1Pless bone marrow-transplanted mice in the thoracic region at 2, 6, and $24 \mathrm{~h}$ a

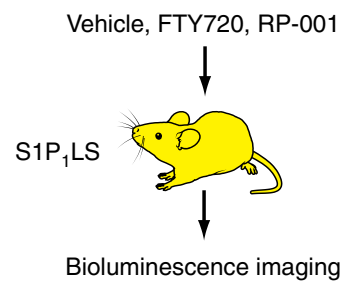

C

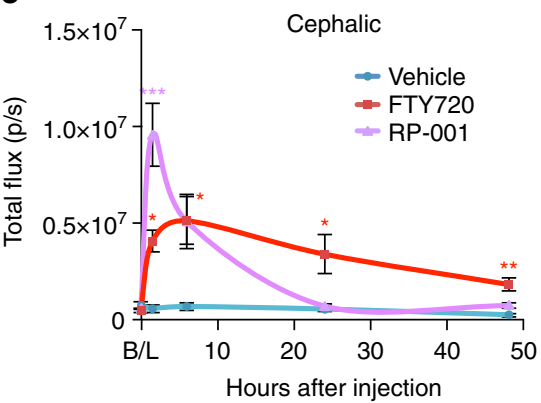

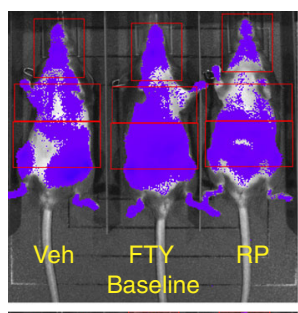
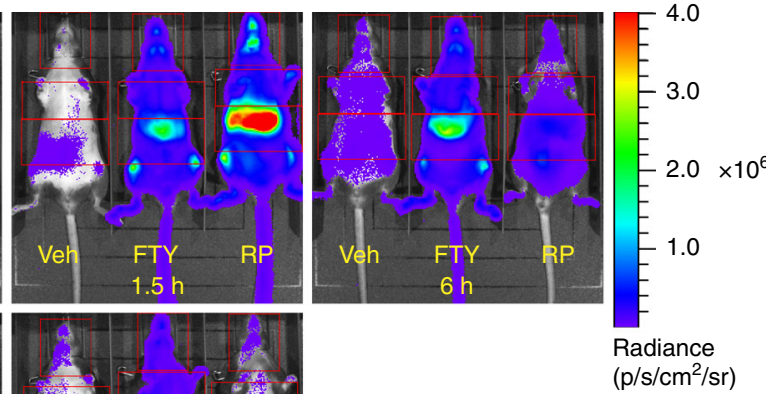

Color scale Min $=1.0 \times 10^{4}$ $\operatorname{Max}=4.0 \times 10^{6}$ d

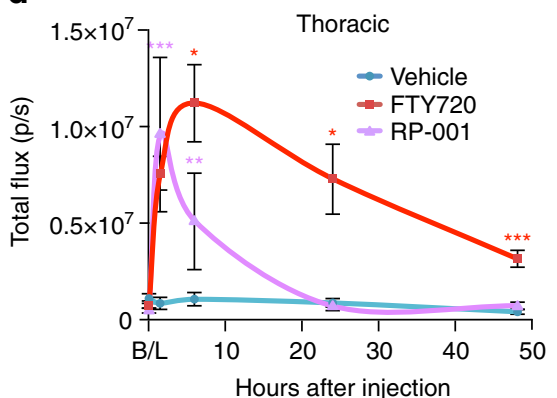

e

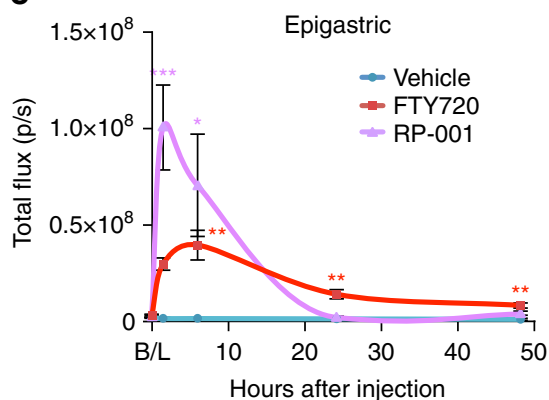

Fig. $3 \mathrm{~S}_{1} \mathrm{P}_{1}$ activation after treatment with $S 1 \mathrm{P}_{1}$ agonists in live mice. a S1P luciferase signaling $\left(S 1 \mathrm{P}_{1} \mathrm{LS}\right)$ mice were intraperitoneally injected with vehicle or the $\mathrm{S1P}_{1}$ agonists FTY720 or RP-001, then subjected to BLI. b Mice were subjected to imaging prior to injection (baseline, B/L) and 1.5, 6, 24, and $48 \mathrm{~h}$ after injection. Representative bioluminescence images of the same three mice comparing the effects of vehicle (Veh), FTY720 (FTY), or RP-001 (RP) at the specified time points. Mice were imaged in the supine position. Red open rectangles representing ROI were positioned around cephalic, thoracic, and epigastric regions. c-e The bioluminescence was quantified by determining the total flux (photons/sec; p/sec) in the cephalic (c), thoracic (d), and epigastric (e) ROI. Data represent the mean \pm SEM. $n=5$ for vehicle, $n=8$ for FTY720, $n=6$ for RP-001. $P$ values between vehicle and agonist-injected groups were determined by one-way ANOVA followed by Bonferroni's multiple comparisons test; ${ }^{\star} P \leq 0.05,{ }^{\star \star} P \leq 0.01,{ }^{\star \star \star} P \leq 0.001$ 
and in the epigastric region at $24 \mathrm{~h}$ (Fig. 5c-f). The residual bioluminescence activity in plasmaS1Pless bone marrowtransplanted mice at $24 \mathrm{~h}$ after LPS treatment was significantly inhibited by the $\mathrm{S}_{1} \mathrm{P}_{1}$ antagonist W146 (Supplementary Fig. 4). These results suggest that the low levels of $\mathrm{dhS1P}$ and S1P remaining in these mice may provide some signaling activity. A high degree of mortality occurred $24 \mathrm{~h}$ after LPS treatment in $\mathrm{S}_{1} \mathrm{P}_{1}$ luciferase signaling mice transplanted with plasmaS1Pless bone marrow, precluding further measurements. These results indicate that hematopoietically derived S1P is responsible for a significant portion of the $\mathrm{S}_{1} \mathrm{P}_{1}$ activation that occurs in vivo during LPS-induced inflammation.

$\mathrm{S}_{1} \mathrm{P}_{1}$ activation in the brain by inflammation. During LPSinduced inflammation, bioluminescence activity was significantly increased in the cephalic region at $24 \mathrm{~h}$ (Fig. $4 \mathrm{~b}, \mathrm{c}$ and Supplementary Fig. 5), raising the possibility that $\mathrm{S}_{1} \mathrm{P}_{1}$ may be activated in the central nervous system (CNS). To determine if $\mathrm{S}_{1} \mathrm{P}_{1}$ signaling was activated within the CNS and, if so, in which cell types, we utilized the previously described $\mathrm{S}_{1} \mathrm{P}_{1}$ GFP signaling mice ${ }^{22}$. In these mice, $\mathrm{S}_{1} \mathrm{P}_{1}$ activation is also based on interaction of the GPCR with $\beta$-arrestin2; however, in this reporter system the interaction leads to the proteolytic release of a transcription factor tethered to $\mathrm{S}_{1} \mathrm{P}_{1}$ that enters the nucleus and activates a histoneGFP reporter gene. The cells in which $\mathrm{S}_{1} \mathrm{P}_{1}$ activation occurs are then stably marked with GFP-labeled nuclei (Fig. 6a). LPS was administered to $\mathrm{S}_{1} \mathrm{P}_{1}$ GFP signaling mice and, 7 days later, brain tissue was collected and sectioned, then the cortex, cerebellum, and brainstem were examined for GFP-labeled cells (Fig. 6b, c).
Compared with vehicle-treated mice, LPS-treated mice exhibited increased numbers of GFP-positive cells in each of these regions, indicating that $\mathrm{S}_{1} \mathrm{P}_{1}$ activation had taken place in the CNS. The GFP-positive cells appeared to be associated with the vasculature and were CD31 positive, establishing their identity as endothelial cells (Fig. 6c). Next, brain endothelial cells were isolated from $\mathrm{S}_{1} \mathrm{P}_{1}$ luciferase signaling mice, treated with $\mathrm{S} 1 \mathrm{P}$ or RP-001, and examined by BLI. Bioluminescent activity was induced in the brain endothelial cells in a dose-dependent manner, with RP-001 exhibiting a higher potency than S1P (Fig. 6d-f). Collectively, the results indicate that $S 1 P_{1}$ is activated in endothelial cells of the neurovascular unit of the brain during systemic inflammation induced by LPS and illustrate that the two different $\mathrm{S}_{\mathrm{P}} \mathrm{P}_{1}$ signaling mouse models provide complementary information for defining $\mathrm{S}_{1} \mathrm{P}_{1}$ activation in vivo.

\section{Discussion}

The luciferase signaling model for GPCR activation described here affords a way to study GPCRs that was not previously possible, yielding spatial and temporal information on the status of endogenous receptor activation in real time in a living animal. The nearly universal interaction between GPCRs with $\beta$ arrestin ${ }^{13}$ was exploited to induce assembly of inactive fragments of luciferase, producing an active enzyme complex and enabling BLI upon activation of a GPCR, $\mathrm{S}_{1} \mathrm{P}_{1}$, in living mice. The in vivo $\mathrm{S}_{1} \mathrm{P}_{1}$ signaling detection system was shown to be activated by both synthetic and natural ligands of $\mathrm{S}_{1} \mathrm{P}_{1}$. BLI of the luciferase signaling mice revealed the anatomical locations of homeostatic $\mathrm{S}_{1} \mathrm{P}_{1}$ signaling, as well as the dynamics of $\mathrm{S}_{1} \mathrm{P}_{1}$ signaling under

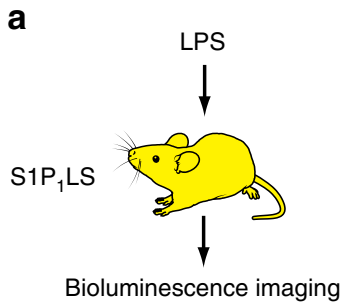

b
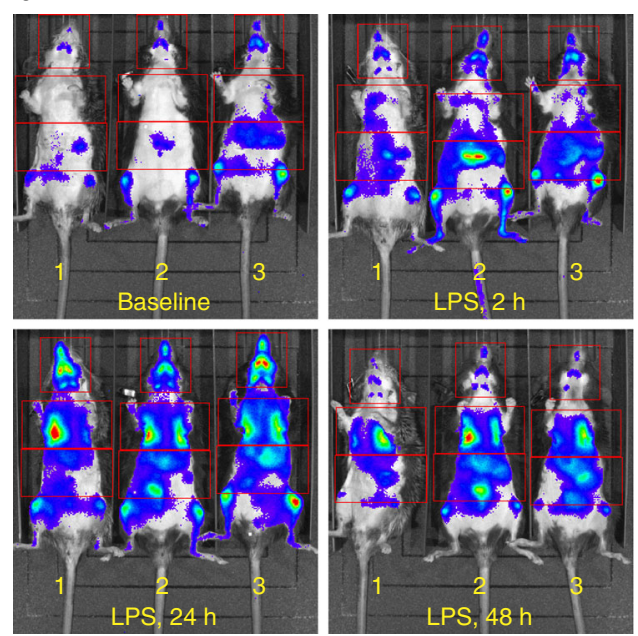

C

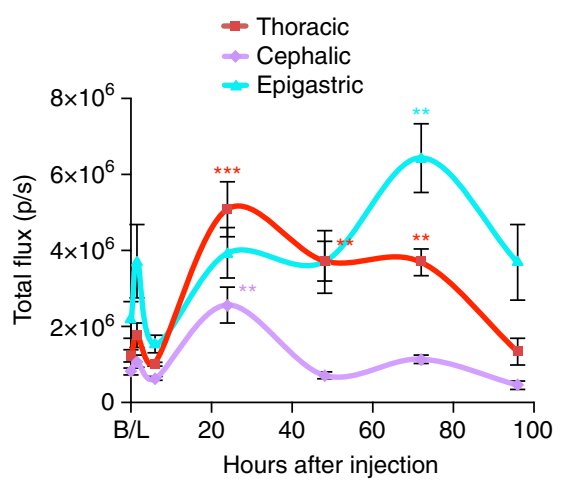

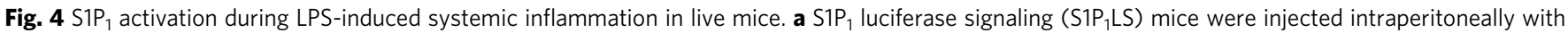
LPS to induce systemic inflammation, then subjected to BLI. $\mathbf{b}$ Representative bioluminescence images of the same three mice prior to LPS injection (baseline, B/L) and 2, 6, 24, 48, and $72 \mathrm{~h}$ after LPS injection. Mice were imaged in the supine position. Red open rectangles representing ROI were positioned around cephalic, thoracic, and epigastric regions. c The bioluminescence activity was quantified by determining the total flux (photons/sec; $\mathrm{p} /$ $\mathrm{sec}$ ) in each ROI. Data represent the mean \pm SEM. $n=5$. $P$ values were determined between baseline and each time point by one-way ANOVA followed by Bonferroni's multiple comparisons test; ${ }^{\star \star} P \leq 0.01,{ }^{\star \star \star} P \leq 0.001$ 
inflammatory conditions. Although the resolution of the luciferase signaling model was limited to the identification of signaling at an organ or tissue level, the associated use of the previously described GFP signaling model for $\mathrm{S}_{1} \mathrm{P}_{1}$ activation $^{22}$, which relies on transcription factor reporter gene activation, provided a means to ultimately define $\mathrm{S}_{1} \mathrm{P}_{1}$ signaling sites at a cellular level. While visualizing the source of the bioluminescent signal with single cell resolution is not possible at present, detection of signaling in realtime in vivo at a single cell level would be an important goal to achieve.

We have demonstrated that the $\mathrm{S}_{1} \mathrm{P}_{1}$ luciferase signaling mice can be used for the characterization of the in vivo signaling activity of the receptor-active pharmacological compounds FTY720 and RP-001 (Fig. 3). FTY720 $0^{10}$, an approved drug (fingolimod/Gilenya ${ }^{\mathrm{TM}}$ ) used for the treatment of multiple sclerosis, targets S1P receptors $1,3,4$, and 5 . It has a relatively long half-life in blood ${ }^{30}$ and has been demonstrated to have diverse physiologic effects in the immune, cardiovascular, and nervous systems ${ }^{7}$. RP001 is an $\mathrm{S}_{1} \mathrm{P}_{1}$-selective agonist that is more potent than FTY720, but with a much shorter half-life in blood. Similar to FTY720, RP001 has been shown to trigger lymphopenia ${ }^{25}$. Administration of these compounds to the $\mathrm{S}_{1} \mathrm{P}_{1}$ luciferase signaling mice enabled determination of the timing of signaling and anatomical location of signaling events, which indicates that this model will be generally useful for characterization of $\mathrm{S}_{1} \mathrm{P}_{1}$ modulators. The signaling induced by RP-001 was relatively intense but decayed rapidly, commensurate with its high potency and short half-life (Fig. 3b-e). The very intense epigastic signal induced by RP-001 may reflect its rapid clearance in the liver. In contrast, the signaling induced by FTY720 in vivo persisted over a long duration, lasting up to $48 \mathrm{~h}$ (Fig. $3 \mathrm{~b}-\mathrm{e}$ ). While consistent with the relatively long half-life of the compound, prolonged signaling, and the apparent absence of rapid desensitization would be compatible with the existence of a receptor reserve. Under normal conditions, a receptor reserve may underpin the long-term tonic $\mathrm{S}_{1} \mathrm{P}_{1}$ signaling in the vascular endothelium. Compartmentalization of $\mathrm{S}_{1} \mathrm{P}_{1}$ receptors may be a mechanism underlying such a receptor reserve $\mathrm{e}^{33,34}$. However, a different mechanism must operate on a

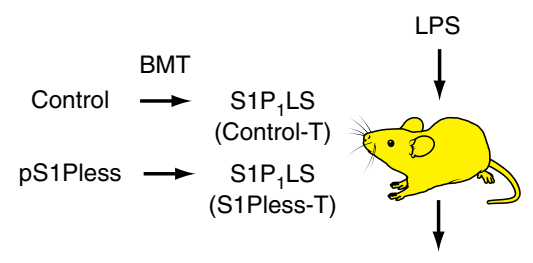

Bioluminescence imaging b

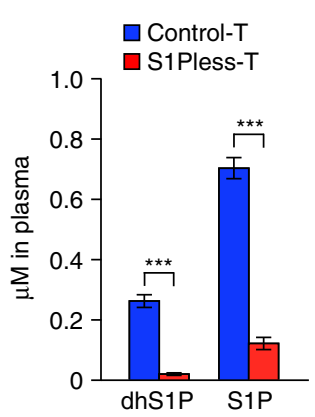

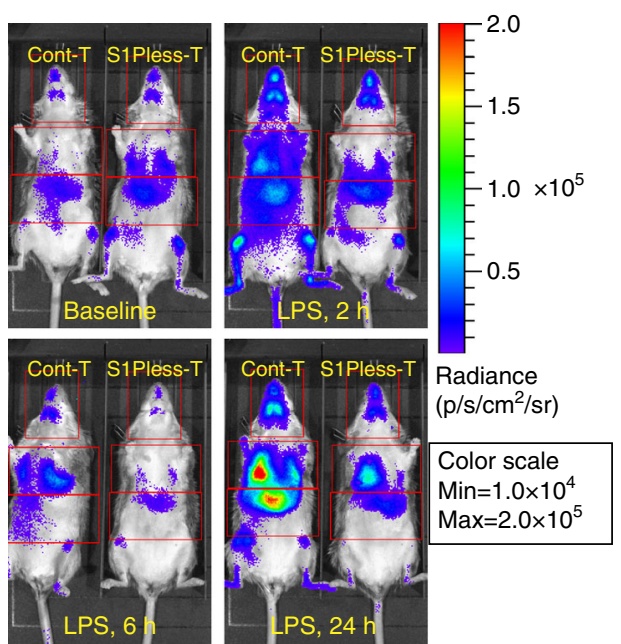

d

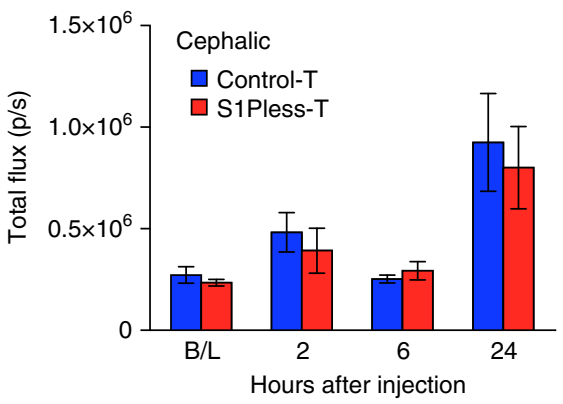

e

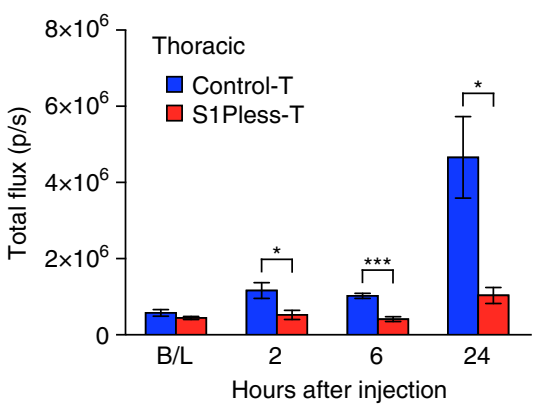

$\mathbf{f}$

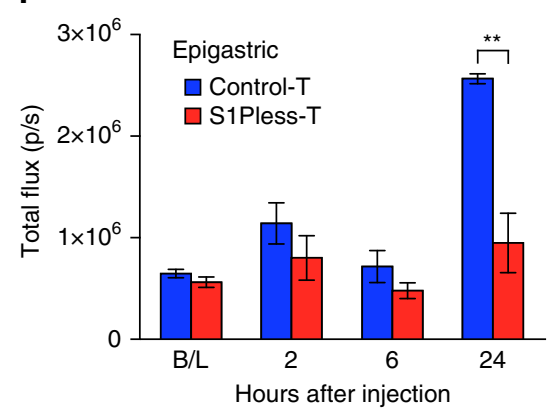

Fig. $5 \mathrm{~S} 1 \mathrm{P}_{1}$ activation during LPS-induced systemic inflammation in live mice transplanted with plasmaS1Pless bone marrow. a Bone marrow cells from control or plasma(p)S1Pless mice were transplanted (BMT) into irradiated $\mathrm{S}_{1} \mathrm{P}_{1}$ luciferase signaling $\left(\mathrm{S}_{\mathrm{P}} \mathrm{LS}\right)$ mice to produce control transplanted (ControlT) or pS1Pless transplanted (S1Pless-T) mice, respectively. LPS was injected intraperitoneally into the stably transplanted mice 20 weeks later. Mice were subjected to BLI prior to the LPS injection (baseline, B/L) and 2, 6, and $24 \mathrm{~h}$ after LPS injection. $\mathbf{b}$ Plasma S1P and dhS1P levels in S1P 1 luciferase signaling mice, transplanted with control (Control-T) or pS1Pless (S1Pless-T) bone marrow. Data represent the mean \pm SEM. $n=6$ for Control-T mice, $n=8$ for S1Pless-T mice. c Representative bioluminescence images of the same S1P luciferase signaling mice, transplanted with control (Cont- $T$ ) or pS1Pless (S1Pless-T) bone marrow, at the specified time points. Mice were imaged in the supine position. Red open rectangles representing ROI were positioned around cephalic, thoracic, and epigastric regions. d-f The bioluminescence activity was quantified by determining the total flux (photons/sec; $\mathrm{p} / \mathrm{sec}$ ) in the cephalic (d), thoracic (e), and epigastric (f) ROI. Data represent the mean \pm SEM. $n=5$ for control BM-transplanted S1P luciferase signaling (Control-T) mice and $n=7$ for pS1Pless BM-transplanted S1P 1 luciferase signaling (S1Pless-T) mice at the baseline, $2 \mathrm{~h}$, and $6 \mathrm{~h}$ time points. $n=4$ for control BMtransplanted $\mathrm{S1P}_{1}$ luciferase signaling (Control-T) mice and $n=6$ for pS1Pless BM-transplanted $\mathrm{S}_{1} \mathrm{P}_{1}$ luciferase signaling (S1Pless-T) mice at $24 \mathrm{~h}$. $P$ values were determined two-tailed Student' $t$-test; ${ }^{\star} P \leq 0.05,{ }^{\star \star} P \leq 0.01,{ }^{\star \star \star} P \leq 0.001$ 
other cell types, such as lymphocytes, that rapidly downmodulate $\mathrm{S}_{1} \mathrm{P}_{1}$ upon exposure to agonist ${ }^{25}$.

The $\mathrm{S}_{1} \mathrm{P}_{1}$ luciferase signaling mice provide the unique capability to detect the signaling activity of the endogenously produced natural ligand under basal and pathophysiological conditions in real time. Under basal conditions, lung and lymphoid tissues showed the highest levels of signaling (Fig. 1i). This is compatible with ample evidence for a functional $\mathrm{S}_{1} \mathrm{P}_{1}$ signaling requirement in these tissues. In lung, blocking $\mathrm{S}_{1} \mathrm{P}_{1}$ signalingeither by removal of S1P from the blood ${ }^{35}$ or by $\mathrm{S}_{1} \mathrm{P}_{1}$ antagonism 28,29 -induced vascular leakage, indicating that $\mathrm{S}_{1} \mathrm{P}_{1}$ signaling is critical to maintain vascular integrity in lung. In lymphoid tissues, $\mathrm{S}_{1} \mathrm{P}_{1}$ signaling has been shown to be necessary for lymphocyte egress ${ }^{36}$ and for the positioning of cells, such as splenic marginal zone $\mathrm{B}$ cells ${ }^{37}$. $\mathrm{S} \mathrm{P}_{1}$ signaling is also required in endothelial cells in lymph nodes, notably on high endothelial venules, which serve as the portals for lymphocyte entry to maintain their vascular integrity ${ }^{38}$.

Under conditions of systemic inflammation induced by LPS exposure, the $\mathrm{S}_{1} \mathrm{P}_{1}$ luciferase signaling mice reported regionspecific dynamics in $\mathrm{S}_{1} \mathrm{P}_{1}$ activation (Fig. 4). Liver showed little or no signaling activity under basal conditions (Fig. 1i), but exhibited dramatically increased $\mathrm{S}_{1} \mathrm{P}_{1}$ signaling during systemic inflammation (Supplementary Fig. 3b). Hepatocytes have been shown to express abundant $\mathrm{S}_{1} \mathrm{P}_{1}$ that is accessible for signaling in response to FTY720 administration ${ }^{22}$. Based on the findings reported here, they are apparently not exposed to sufficient S1P under basal conditions to stimulate signaling. However, during conditions that induce vascular leakage, such as inflammation, $\mathrm{S} 1 \mathrm{P}$ derived from blood sources can stimulate $\mathrm{S}_{1} \mathrm{P}_{1}$ signaling in hepatocytes and endothelial cells of liver, and endothelial cells in lung, as has been demonstrated in an $\mathrm{S}_{1} \mathrm{P}_{1}$ GFP signaling mouse model $^{22}$. We have extended these finding here by showing increased $\mathrm{S}_{1} \mathrm{P}_{1}$ signaling in brain endothelial cells during systemic inflammation (Fig. 6).

The strategy used to produce the $\mathrm{S}_{1} \mathrm{P}_{1}$ luciferase signaling mice provides a template for the development of a library of other GPCR-signaling models. Creation of models for other GPCRs that similarly interact with $\beta$-arrestin 2 should only require the derivation of a mouse with a receptor knock-in of the C-terminal Luc fragment (amino acids \#394-550). Subsequent cross-breeding with the NLuc- $\beta$-arrestin 2 mouse described here, which carries the complementary luciferase N-terminal fragment (amino acids \#1-416), would yield unique GPCR-signaling models. These a

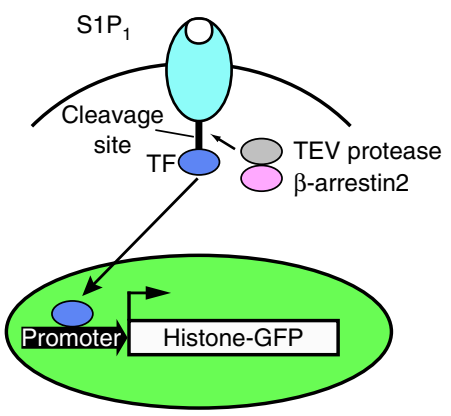

C
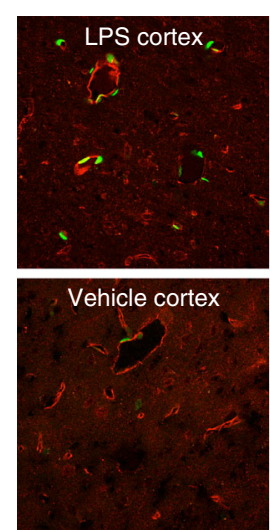

CD31/S1P, activation
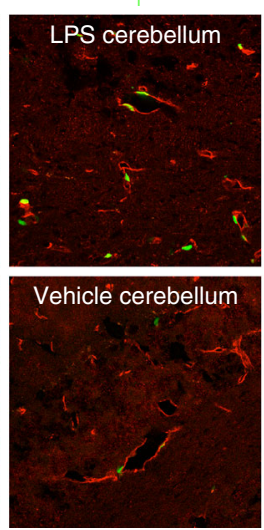

b

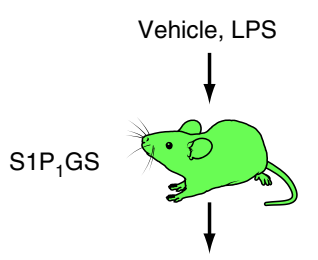

Brain immunofluorescence d
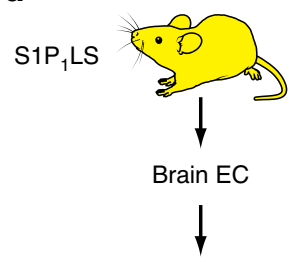

S1P, RP-001

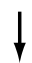

Bioluminescence imaging
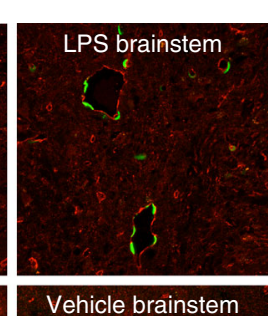

e

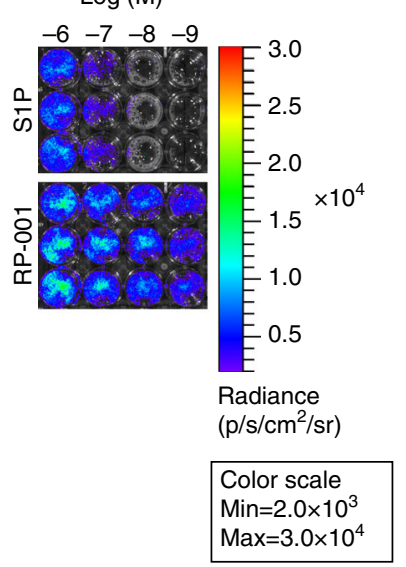

$\mathbf{f}$

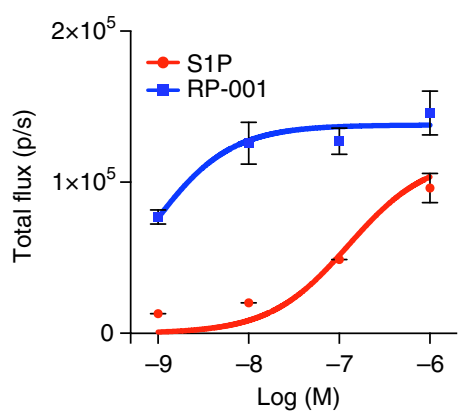

Fig. $6 \mathrm{STP}_{1}$ activation by LPS in the brain. a Schematic of the design to monitor S1P $\mathrm{P}_{1}$ activation in S1P $\mathrm{P}_{1}$ GFP signaling mice. S1P 1 is fused to a transcription factor (TF) via a protease recognition sequence. Ligand binding to the receptor stimulates the recruitment of a $\beta$-arrestin2-TEV protease fusion protein, triggering the release of the transcription factor from the $C$ terminus of modified $\mathrm{S1P}_{1}$. The transcription factor stimulates expression of a histone-GFP reporter gene, fluorescently labeling cell nuclei. $\mathbf{b}$ LPS or vehicle was injected intraperitoneally into $\mathrm{S}_{1} \mathrm{P}_{1}$ GFP signaling $\left(S 1 \mathrm{P}_{1} \mathrm{GS}\right)$ mice, and the brains were harvested 7 days after injection and examined by immunofluorescence. The tissues of three mice injected with LPS and three mice injected with vehicle were examined. c Representative histological sections were immunostained with antibodies to CD31, and the images of cerebral cortex, cerebellum, and brainstem were captured using an inverted laser scanning confocal microscope. Scale bar, $50 \mu \mathrm{m}$. d Brain endothelial cells (EC) were isolated from S1P luciferase signaling $\left(\mathrm{S} 1 \mathrm{P}_{1} \mathrm{LS}\right)$ mice, grown in triplicate in 24-well plates, treated with S1P or RP-001 and D-luciferin, and immediately subjected to BLI. e Bioluminescence images of the cells exposed to the indicated concentrations of S1P or RP-001 represent a 15-min acquisition. The experiment was repeated twice. $\mathbf{f}$ The bioluminescence activity was quantified by determining the total flux (photons $/ \mathrm{sec} ; \mathrm{p} / \mathrm{sec}$ ). Data represent the mean $\pm \mathrm{SEM}, n=6$ 
models can be used to gain new understandings of GPCR signaling in normal and disease-specific biological contexts, and enable in vivo analysis of GPCR-signaling perturbation by receptor-active compounds, thereby facilitating drug development for this important target class.

\section{Methods}

Reagents. S1P (d18:1), sphingosine (d18:1), and LPA (18:1) were purchased from Avanti Polar Lipids; dhS1P (d18:0), LPS (Escherichia coli 055:B5; L2880), and polyinosinic-polycytidylic ribonucleic acid (pIpC) (P0913) from Sigma-Aldrich; FTY720 and W146 from Cayman; and RP-001 from Tocris.

Generation of S1P $\mathbf{1}$ luciferase signaling mice. A split firefly luciferase enzyme complementation system ${ }^{23,24}$ (Fig. 1a) was designed for detection of the $\mathrm{S1P}_{1}$ and $\beta$-arrestin2 interaction after receptor activation. The fragments were fused to the mouse S1pr1 (Accession: NM_007901.5) or Arrb2 (Accession: NM_145429.5) coding regions via a linker (GGGGSGGGGS); the S1prl coding region was linked to the C-terminal luciferase fragment (amino acids \#394-550) to produce the $\mathrm{S}_{1} \mathrm{P}_{1}$-CLuc fusion and the Arrb2 coding region was linked to the $\mathrm{N}$-terminal luciferase fragment (amino acids \#1-416) to produce the NLuc- $\beta$-arrestin2 fusion. Targeting vectors for mouse embryonic stem cells were constructed to insert the $S 1 \mathrm{P}_{1}$-CLuc or NLuc- $\beta$-arrestin2 fusions into the S1pr1 or Rosa26 locus, respectively (Supplementary Fig. 2a, b). In the S1pr1-targeting vector, the neomycin resistance gene (NeoR), flanked by loxP sites, was inserted downstream of the fusion gene. In the Rosa26-targeting vector ${ }^{39}$, NeoR and a stop cassette (NeoR Stop), flanked by loxP sites, was placed upstream of the fusion gene. Gene targeting in embryonic stem cells and generation of chimeric and heterozygous mice were conducted as described previously ${ }^{22}$. The genotypes were determined by PCR analysis of genomic DNA isolated from mouse tails. For genotyping of the $\mathrm{S} \mathrm{P}_{1}$-CLuc fusion knock-in mice carrying NeoR, three primers were used: $5^{\prime}$ AGAGGAATGTGGGCTGTTGATCCT-3' (Primer 1); 5' -GGTGAACATCCACCCACTATTCCA-3' (Primer 2); and 5'-CCAAATTAAGGGCCAGCTCATTCC-3' (Primer 3). Primers 1 and 2 detected the wild-type (WT) allele and amplified a 290-bp fragment. Primers 2 and 3 detected the knock-in allele carrying NeoR and amplified a 400-bp fragment. Forty cycles of $94^{\circ} \mathrm{C}$ $(1 \mathrm{~min}), 60^{\circ} \mathrm{C}(1 \mathrm{~min})$, and $72^{\circ} \mathrm{C}(1.5 \mathrm{~min})$ were used for PCR. For genotyping of the NLuc- $\beta$-arrestin2 knock-in mice bearing NeoR stop, three primers were used: 5'-GCACTTGCTCTCCCAAAGTC-3' (Primer 4); 5'-GGCGGATCACAAGCAATAAT- $3^{\prime}$ (Primer 5); and 5'-TACCGGTGGATGTGGAATGT-3' (Primer 6). Primers 4 and 5 detected the WT allele and amplified a 450-bp fragment. Primers 4 and 6 detected the knock-in allele bearing NeoR and the stop codon and amplified a 580-bp fragment. Forty cycles of $94^{\circ} \mathrm{C}(1 \mathrm{~min}), 63^{\circ} \mathrm{C}(1 \mathrm{~min})$, and $72{ }^{\circ} \mathrm{C}(1.5 \mathrm{~min})$ were used for PCR.

An EIIa Cre recombinase transgenic line $e^{40}$ (stock $\# 003724$, The Jackson Laboratory) was crossed with the knock-in mice to remove the loxP-flanked genes in the germline. For genotyping of the $\mathrm{S} \mathrm{P}_{1}$-CLuc knock-in mice with NeoR excised (-NeoR), three primers were used. Primers 1 and 7 (5'-

AGATGGCGGTAACTCTGAGG- ${ }^{\prime}$ ) detected the WT allele and amplified a $400-$ bp fragment. Primers 7 and 8 (5'-TAGTTGCCAGCCATCTGTTGTTTG- $3^{\prime}$ ) detected the $\mathrm{S}_{1} \mathrm{P}_{1}$-CLuc (-NeoR) knock-in allele and amplified a 510-bp fragment. Forty cycles of $95^{\circ} \mathrm{C}(1 \mathrm{~min}), 63^{\circ} \mathrm{C}(1 \mathrm{~min})$, and $72^{\circ} \mathrm{C}(1.5 \mathrm{~min})$ were used for PCR. For genotyping of the NLuc- $\beta$-arrestin2 (-NeoR Stop) knock-in mice, three primers were used. Primers 4 and 5 detected the WT allele as described above, and primers 4 and $9\left(5^{\prime}\right.$-CCGTCTTCGAGTGGGTAGAA-3') detected the NLuc- $\beta$ arrestin2 (-NeoR Stop) knock-in allele and amplified a 560-bp fragment. Forty cycles of $95^{\circ} \mathrm{C}(1 \mathrm{~min}), 63^{\circ} \mathrm{C}(1 \mathrm{~min})$, and $72^{\circ} \mathrm{C}(1.5 \mathrm{~min})$ were used for PCR

The scheme to derive $\mathrm{SIP}_{1}$ luciferase signaling mice is shown in Fig. 1a. Mice heterozygous for $\mathrm{S}_{\mathrm{P}} \mathrm{P}_{1}$-CLuc (-NeoR) knock-in mice were crossed with mice heterozygous for NLuc- $\beta$-arrestin2 (-NeoR) knock-in mice to obtain double heterozygotes, which were back crossed to mice heterozygous for NLuc- $\beta$-arrestin2 $(-\mathrm{NeoR})$ to obtain mice heterozygous for $\mathrm{S}_{1} \mathrm{P}_{1}-\mathrm{CLuc}(-\mathrm{NeoR})$ and homozygous for NLuc- $\beta$-arrestin2 (-NeoR). S1P 1 luciferase signaling mice that were heterozygous for the $\mathrm{S}_{1} \mathrm{P}_{1}-\mathrm{CLuc}(-\mathrm{NeoR})$ allele and homozygous for the NLuc- $\beta$-arrestin2 (-NeoR Stop) allele showed a higher bioluminescence signal after FTY720 treatment than mice heterozygous for both of these alleles (Supplementary Fig. 6). For this reason, mice heterozygous for the $\mathrm{S}_{\mathrm{P}} \mathrm{P}_{1}-\mathrm{CLuc}(-\mathrm{NeoR})$ allele and homozygous for the NLuc- $\beta$-arrestin2 (-NeoR stop) allele were used in S1P1 luciferase signaling mouse studies. Animals were housed in a specific pathogen-free facility and provided food and water ad libitum. Age-matched offspring of both sexes (2-5 months old) were used for experiments. The mice were at the initiation of experiments. The sample size was selected based on expected effect size. No randomization method was employed. Investigators were blinded to the genotype of animals during data analysis. No experimental animals were excluded from the analysis.

BLI of S1P $\mathbf{P}_{1}$ activation in cells and mice. S1P ${ }_{1}-C L u c, N L u c-\beta$-arrestin2, and NLuc-HSV-tk (accession: Q9QNF7.1) fusions were prepared using a linker (GGGGSGGGGS) sequence as described above and cloned into pcDNA3.1
(Thermo Fisher Scientific). U2OS cells (American Type Culture Collection) were plated in 24-well plates $\left(1.5 \times 10^{5}\right.$ cells/well $)$ and transfected by pcDNA3.1$\mathrm{S}_{1} \mathrm{P}_{1}$-CLuc $(10 \mathrm{ng})$ together with pcDNA3.1-NLuc- $\beta$-arrestin2 (500 ng) or pcDNA3.1-NLuc-HSV-tk (500 ng) using Lipofectamine 3000 (Thermo Fisher Scientific). The media was replaced $24 \mathrm{~h}$ after transfection with DMEM containing $10 \%$ charcoal-stripped FBS and the cells incubated for $16 \mathrm{~h}$. The media was then changed to DMEM with $0.1 \%$ FBS for $4 \mathrm{~h}$, and then treated simultaneously with $150 \mu \mathrm{g} / \mathrm{ml}$ D-luciferin ( $\mathrm{K}+$ Salt Bioluminescent Substrate, PerkinElmer) and S1P, RP-001, or vehicle. Bioluminescence activity was immediately detected with an in vivo imaging system (IVIS Lumina II, PerkinElmer).

$\mathrm{S}_{1} \mathrm{P}_{1}$ luciferase signaling MEFs were isolated from E12.5 embryos with three different genotypes: heterozygous for the $\mathrm{S}_{1} \mathrm{P}_{1}$-CLuc allele; homozygous for the NLuc- $\beta$-arrestin2 allele; and heterozygous for the $\mathrm{S}_{1} \mathrm{P}_{1}-\mathrm{CLuc}$ allele and homozygous for the NLuc- $\beta$-arrestin2 allele ( $\mathrm{S}_{\mathrm{P}} \mathrm{P}_{1}$ luciferase signaling mice). The MEFs were plated in 24-well plates $\left(2 \times 10^{5}\right.$ cells/well $)$ and incubated for $16 \mathrm{~h}$ in DMEM containing $10 \%$ charcoal-stripped FBS for $16 \mathrm{~h}$ followed by DMEM with $0.1 \% \mathrm{FBS}$ for $4 \mathrm{~h}$. After treatment with agonists, bioluminescence activity was measured immediately as described above.

$\mathrm{S}_{1} \mathrm{P}_{1}$ luciferase signaling mouse brain endothelial cells were prepared as previously described ${ }^{41}$. The endothelial cells in 24 -well plates $\left(10^{5} /\right.$ well) were incubated in medium (DMEM high glucose [12-709 F, LONZA], $5 \mu \mathrm{g} / \mathrm{ml}$ endothelial cell growth factor [BT-203, Biomed Tech], $100 \mu \mathrm{g} / \mathrm{ml}$ heparin, $100 \mathrm{U} /$ $\mathrm{ml}$ penicillin, and $100 \mathrm{U} / \mathrm{ml}$ streptomycin) containing $10 \%$ charcoal-stripped FBS for $16 \mathrm{~h}$ followed by medium containing $0.1 \%$ BSA for $4 \mathrm{~h}$. After treatment with agonists, bioluminescence activity was immediately detected as described above.

For BLI in live mice, the hair was removed with a clipper and hair removal cream. XenoLight Rediject D-luciferin (PerkinElmer) $(150 \mathrm{mg} / \mathrm{kg} \mathrm{BW})$ was injected intraperitoneally, and the mice were subjected to BLI using an in vivo imaging system (IVIS Lumina II). During the imaging, the mice were anesthetized with isoflurane (Baxter) using an XGI-8 gas anesthesia system (PerkinElmer). Eye lubricant (Puralube Vet Ointment, Dechra) was applied during the anesthesia. Imaging parameters were: binning $=$ medium (8), field of view $=12.5 \times 12.5 \mathrm{~cm}, \mathrm{f} /$ stop $=1$. Each image exposure lasted $5 \mathrm{~min}$, and a total of four sequential images were captured. The second 5-min image was used in all experiments. Images were analyzed using Living Image Software (PerkinElmer). Regions of interest (ROI) were drawn around each body region and the total flux (photons/s) was determined.

For BLI of internal organs, mice were anesthetized by intraperitoneal injection of ketamine (180 mg/kg BW)-xylazine (12 mg/kg BW), and after $15 \mathrm{~min}$ received an intraperitoneal XenoLight Rediject D-luciferin (PerkinElmer) injection $(500 \mathrm{mg} / \mathrm{kg} \mathrm{BW})$. The ventral skin was incised along the midline to expose the internal organs. Bioluminescence activity was immediately detected with an in vivo imaging system (IVIS Lumina II) with four acquisitions lasting $5 \mathrm{~min}$ each.

In some mouse studies, prior to imaging, mice were intraperitoneally injected with FTY720 (1 mg/kg BW; vehicle, 43\% ethanol-7\% DMSO in PBS), RP-001 $(1 \mathrm{mg} / \mathrm{kg} \mathrm{BW}$; vehicle, $43 \%$ ethanol-7\% DMSO in PBS), W146 (5 and $10 \mathrm{mg} / \mathrm{kg}$ BW; vehicle, $10 \mathrm{mM}$ sodium carbonate-2\% (2-hydroxypropyl)- $\beta$-cyclodextrin in water), or LPS (16 mg/kg BW; vehicle, PBS).

Analysis of S1P $_{1}$ activation in brain. $\mathrm{S}_{1} \mathrm{P}_{1}$ GFP signaling mice have been previously described ${ }^{22}$. LPS (16 mg/kg BW; vehicle, PBS) was injected intraperitoneally into $\mathrm{S}_{1} \mathrm{P}_{1}$ GFP signaling mice. Seven days after the injection, the mice were perfused with normal saline followed by chilled $4 \%$ paraformaldehyde in $0.1 \mathrm{M}$ phosphate buffer $(\mathrm{pH}$ 7.4) and the brains were harvested. The tissues were post fixed in $4 \%$ paraformaldehyde for $4 \mathrm{~h}$ and incubated in $30 \%$ sucrose in $0.1 \mathrm{M}$ phosphate buffer ( $\mathrm{pH} \mathrm{7.4)}$ at $4^{\circ} \mathrm{C}$ for 2 days, then embedded in OCT (Sakura) and sectioned at $7-\mu \mathrm{m}$ thickness. For immunostaining, nonconjugated primary antibody for mouse CD31 (clone SZ31, Dianova) and fluorescently labeled secondary antibody (donkey anti-rat IgG Cyanine Cy3, Jackson ImmunoResearch Laboratories) were used. The images were captured with an inverted laser scanning confocal microscope (LSM 780, Carl Zeiss Microscopy) using Zeiss Zen 2012 software.

\section{Preparation of plasma S1P-deficient S1P luciferase signaling mice}

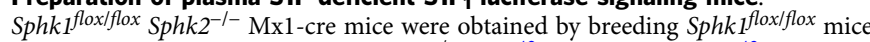

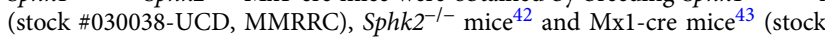
\#003556, The Jackson Laboratory). Plasma S1P-deficient (plasmaS1Pless) mice

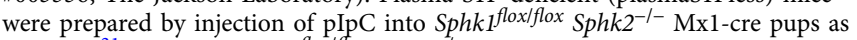
described ${ }^{31}$. Controls $\left(S p h k 1^{\text {flox/flox }} S p h k 2^{-l-}\right.$ ) were similarly bred and injected with pIpC. Bone marrow cells were isolated from the femurs and tibias of adult control and plasmaS1Pless mice 4 weeks after $\mathrm{pIpC}$ injection. A single cell suspension of control or plasmaS1Pless bone marrow cells $\left(1 \times 10^{7}\right.$ cells/mouse $)$ in $0.2 \mathrm{ml}$ saline was injected into the tail vein of irradiated $(9 \mathrm{~Gy}) \mathrm{S}_{1} \mathrm{P}_{1}$ luciferase signaling mice. These mice, termed control and plasmaS1Pless $\mathrm{S}_{1} \mathrm{P}_{1}$ luciferase signaling mice, respectively, were used 20 weeks after transplantation.

Sphingolipid analysis. S1P and dhS1P were measured by HPLC-tandem MS by the Lipidomics Core at the Medical University of South Carolina on a Thermo Finnigan TSQ 7000 triple quadrupole mass spectrometer (Thermo Fisher 
Scientific), operating in a multiple reaction monitoring-positive ionization mode as described ${ }^{44}$.

Statistical analysis. GraphPad Prism v.6.0 software was used for statistical analyses. To determine the significance between three or more test groups, analysis of variance (ANOVA) was used followed by either Bonferroni's for comparison to the control group or Tukey's to compare all groups. Two-tailed Student's $t$-test was used for the direct comparison of two groups. In all cases, $P \leq 0.05$ was considered statistically significant.

Study approval. All animal procedures were approved by the Animal Care and Use Committee of the National Institute of Diabetes and Digestive and Kidney Diseases and performed in accordance with the National Institutes of Health guidelines.

Data availability. The authors declare that all data supporting the findings of this study are available within this paper or its Supplementary Information file or are available from the corresponding author on request.

Received: 24 June 2016 Accepted: 6 September 2017

Published online: 27 October 2017

\section{References}

1. Jassal, B. et al. The systematic annotation of the three main GPCR families in Reactome. Database 2010, baq018 (2010).

2. Fredriksson, R., Lagerstrom, M. C., Lundin, L. G. \& Schioth, H. B. The Gprotein-coupled receptors in the human genome form five main families. Phylogenetic analysis, paralogon groups, and fingerprints. Mol. Pharmacol. 63, 1256-1272 (2003).

3. Ezkurdia, I. et al. Multiple evidence strands suggest that there may be as few as 19,000 human protein-coding genes. Hum. Mol. Genet. 23, 5866-5878 (2014).

4. Roth, B. L. \& Kroeze, W. K. Integrated approaches for genome-wide interrogation of the druggable non-olfactory g protein-coupled receptor superfamily. J. Biol. Chem. 290, 19471-19477 (2015).

5. Hopkins, A. L. \& Groom, C. R. The druggable genome. Nat. Rev. Drug Discov. 1, 727-730 (2002)

6. Rosen, H., Germana Sanna, M., Gonzalez-Cabrera, P. J. \& Roberts, E. The organization of the sphingosine 1-phosphate signaling system. Curr. Top Microbiol. Immunol. 378, 1-21 (2014).

7. Proia, R. L. \& Hla, T. Emerging biology of sphingosine-1-phosphate: its role in pathogenesis and therapy. J. Clin. Invest. 125, 1379-1387 (2015).

8. Regard, J. B., Sato, I. T. \& Coughlin, S. R. Anatomical profiling of G proteincoupled receptor expression. Cell 135, 561-571 (2008).

9. Maceyka, M. \& Spiegel, S. Sphingolipid metabolites in inflammatory disease. Nature 510, 58-67 (2014).

10. Brinkmann, V. et al. Fingolimod (FTY720): discovery and development of an oral drug to treat multiple sclerosis. Nat. Rev. Drug Discov. 9, 883-897 (2010).

11. Gilman, A. G. G proteins: transducers of receptor-generated signals. Annu. Rev. Biochem. 56, 615-649 (1987).

12. Allen, J. A. \& Roth, B. L. Strategies to discover unexpected targets for drugs active at G protein-coupled receptors. Annu. Rev. Pharmacol. Toxicol. 51, 117-144 (2011).

13. Lefkowitz, R. J. \& Shenoy, S. K. Transduction of receptor signals by betaarrestins. Science 308, 512-517 (2005).

14. Shenoy, S. K. \& Lefkowitz, R. J. Beta-arrestin-mediated receptor trafficking and signal transduction. Trends Pharmacol. Sci. 32, 521-533 (2011).

15. Lee, M. H. et al. The conformational signature of beta-arrestin2 predicts its trafficking and signalling functions. Nature 531, 665-668 (2016).

16. Wisler, J. W., Xiao, K., Thomsen, A. R. \& Lefkowitz, R. J. Recent developments in biased agonism. Curr. Opin. Cell Biol. 27, 18-24 (2014).

17. Barnea, G. et al. The genetic design of signaling cascades to record receptor activation. Proc. Natl Acad. Sci. USA 105, 64-69 (2008).

18. Kroeze, W. K. et al. PRESTO-Tango as an open-source resource for interrogation of the druggable human GPCRome. Nat. Struct. Mol. Biol. 22, 362-369 (2015).

19. von Degenfeld, G., Wehrman, T. S., Hammer, M. M. \& Blau, H. M. A universal technology for monitoring G-protein-coupled receptor activation in vitro and noninvasively in live animals. FASEB J. 21, 3819-3826 (2007)

20. Barak, L. S., Ferguson, S. S., Zhang, J. \& Caron, M. G. A beta-arrestin/green fluorescent protein biosensor for detecting $\mathrm{G}$ protein-coupled receptor activation. J. Biol. Chem. 272, 27497-27500 (1997).

21. Hattori, M. \& Ozawa, T. Live cell bioluminescence imaging in temporal reaction of $\mathrm{g}$ protein-coupled receptor for high-throughput screening and analysis. Methods Mol. Biol. 1461, 195-202 (2016).
22. Kono, M. et al. Sphingosine-1-phosphate receptor 1 reporter mice reveal receptor activation sites in vivo. J. Clin. Invest. 124, 2076-2086 (2014).

23. Paulmurugan, R., Umezawa, Y. \& Gambhir, S. S. Noninvasive imaging of protein-protein interactions in living subjects by using reporter protein complementation and reconstitution strategies. Proc. Natl Acad. Sci. USA 99, 15608-15613 (2002).

24. Paulmurugan, R. \& Gambhir, S. S. Combinatorial library screening for developing an improved split-firefly luciferase fragment-assisted complementation system for studying protein-protein interactions. Anal. Chem. 79, 2346-2353 (2007).

25. Cahalan, S. M. et al. Actions of a picomolar short-acting S1P(1) agonist in S1P (1)-eGFP knock-in mice. Nat. Chem. Biol. 7, 254-256 (2011).

26. Liu, C. H. et al. Ligand-induced trafficking of the sphingosine-1-phosphate receptor EDG-1. Mol. Biol. Cell 10, 1179-1190 (1999).

27. Van Brocklyn, J. R. et al. Dual actions of sphingosine-1-phosphate: extracellular through the Gi-coupled receptor Edg-1 and intracellular to regulate proliferation and survival. J. Cell Biol. 142, 229-240 (1998).

28. Sanna, M. G. et al. Enhancement of capillary leakage and restoration of lymphocyte egress by a chiral S1P1 antagonist in vivo. Nat. Chem. Biol. 2, 434-441 (2006).

29. Tarrason, G. et al. The sphingosine-1-phosphate receptor-1 antagonist, W146, causes early and short-lasting peripheral blood lymphopenia in mice. Int. Immunopharmacol. 11, 1773-1779 (2011).

30. Meno-Tetang, G. M. et al. Physiologically based pharmacokinetic modeling of FTY720 (2-amino-2[2-(-4-octylphenyl)ethyl]propane-1,3-diol hydrochloride) in rats after oral and intravenous doses. Drug Metab. Dispos. 34, 1480-1487 (2006).

31. Pappu, R. et al. Promotion of lymphocyte egress into blood and lymph by distinct sources of sphingosine-1-phosphate. Science 316, 295-298 (2007).

32. Fukuhara, S. et al. The sphingosine-1-phosphate transporter Spns2 expressed on endothelial cells regulates lymphocyte trafficking in mice. J. Clin. Invest. 122, 1416-1426 (2012).

33. Rosen, H., Stevens, R. C., Hanson, M., Roberts, E. \& Oldstone, M. B. Sphingosine-1-phosphate and its receptors: structure, signaling, and influence. Annu. Rev. Biochem. 82, 637-662 (2013).

34. Means, C. K., Miyamoto, S., Chun, J. \& Brown, J. H. S1P1 receptor localization confers selectivity for Gi-mediated cAMP and contractile responses. J. Biol. Chem. 283, 11954-11963 (2008).

35. Camerer, E. et al. Sphingosine-1-phosphate in the plasma compartment regulates basal and inflammation-induced vascular leak in mice. J. Clin. Invest. 119, 1871-1879 (2009)

36. Cyster, J. G. \& Schwab, S. R. Sphingosine-1-phosphate and lymphocyte egress from lymphoid organs. Annu. Rev. Immunol. 30, 69-94 (2012).

37. Arnon, T. I. \& Cyster, J. G. Blood, sphingosine-1-phosphate and lymphocyte migration dynamics in the spleen. Curr. Top Microbiol. Immunol. 378, 107-128 (2014).

38. Herzog, B. H. et al. Podoplanin maintains high endothelial venule integrity by interacting with platelet CLEC-2. Nature 502, 105-109 (2013).

39. Srinivas, S. et al. Cre reporter strains produced by targeted insertion of EYFP and ECFP into the ROSA26 locus. BMC Dev. Biol. 1, 4 (2001).

40. Lakso, M. et al. Efficient in vivo manipulation of mouse genomic sequences at the zygote stage. Proc. Natl Acad. Sci. USA 93, 5860-5865 (1996).

41. Wu, Z., Hofman, F. M. \& Zlokovic, B. V. A simple method for isolation and characterization of mouse brain microvascular endothelial cells. J. Neurosci. Methods 130, 53-63 (2003).

42. Mizugishi, K. et al. Essential role for sphingosine kinases in neural and vascular development. Mol. Cell Biol. 25, 11113-11121 (2005).

43. Kuhn, R., Schwenk, F., Aguet, M. \& Rajewsky, K. Inducible gene targeting in mice. Science 269, 1427-1429 (1995)

44. Bielawski, J., Szulc, Z. M., Hannun, Y. A. \& Bielawska, A. Simultaneo us quantitative analysis of bioactive sphingolip ids by high-perfor mance liquid chromatography-tandem mass spectrometry. Methods 39, 82-91 (2006).

\section{Acknowledgements}

This research was supported by the Intramural Research Programs of the National Institutes of Health, National Institute of Diabetes and Digestive and Kidney Diseases (RLP), NIH Grant HL89934 (T.H.), and the Fondation Leducq Transatlantic Network (R.L.P. and T.H.). K.Y. is supported by the Japan Society for the Promotion of Science postdoctoral fellowship. We are very grateful to Tara Brown for help with cloning and Terry Lee for assistance in the data analysis. We thank Linda Raab for expert editing of the manuscript and Galina Tuymetova for supplying the Sphk mutant mice.

\section{Author contributions}

M.K. designed and performed experiments, analyzed and interpreted data, and wrote the manuscript. E.G.C. and S.Y.L. performed experiments and analyzed data. K.Y. and T.H. contributed to the brain endothelial cell studies and analyzed data. R.L.P. supervised the 
overall project, helped design experiments, analyzed and interpreted data, and wrote the manuscript. All authors read and commented on the manuscript.

\section{Additional information}

Supplementary Information accompanies this paper at doi: 10.1038/s41467-017-01340-7.

Competing interests: The authors declare no competing financial interests.

Reprints and permission information is available online at http://npg.nature.com/ reprintsandpermissions/

Publisher's note: Springer Nature remains neutral with regard to jurisdictional claims in published maps and institutional affiliations. (c) (i) Open Access This article is licensed under a Creative Commons Attribution 4.0 International License, which permits use, sharing, adaptation, distribution and reproduction in any medium or format, as long as you give appropriate credit to the original author(s) and the source, provide a link to the Creative Commons license, and indicate if changes were made. The images or other third party material in this article are included in the article's Creative Commons license, unless indicated otherwise in a credit line to the material. If material is not included in the article's Creative Commons license and your intended use is not permitted by statutory regulation or exceeds the permitted use, you will need to obtain permission directly from the copyright holder. To view a copy of this license, visit http://creativecommons.org/ licenses/by/4.0/.

(C) The Author(s) 2017 